\title{
Changes in Pectic Fractions during Ripening of Cider Apples
}

\author{
J.J. Mangas, E. Dapena, M.S. Rodriguez, and J. Moreno \\ Centro de Experimentación Agraria, Consejería de Agricultura y Pesca \\ del Principado de Asturias, 33300 Villaviciosa, Asturias, Spain
}

\author{
M.D. Gutiérrez and D. Blanco \\ Departamento de Química Física y Analítica, Universidad de Oviedo, \\ 33006 Oviedo, Asturias, Spain
}

Additional index words. Malus domestics, maturity, processing

\begin{abstract}
Water-soluble pectin (WSP), chelator-soluble pectin (CSP), and hydrochloric acid-soluble pectin (HASP) were monitored in five Asturian apples (Malus domestics Borkh.) throughout ripening. The alcohol-insoluble solid content was found to decrease during ripening, while those of the WSP and CSP fractions increased in the final stages of ripening. This increase was probably at the expense of the HASP content, which had decreased by the end of the ripening period.
\end{abstract}

Pectins are known to include a rhamnogalacturonan backbone in which 1-4 linked a-D-galacturonan chains are disrupted by kinks arising from L-rhamnopyranosyl residues bearing neutral side chains consisting basically of L,-arabinose, D-galactose, and Dxylose (Meurens, 1977; Saulnier and Brillouet, 1988). These neutral sugar side chains tend to form blocks that result in hairy regions (De Vries et al., 1982) and link pectins with hemicelluloses.

The components of the cell wall and middle lamella of the pulp cells in apples undergo significant structural variations during ripening, thus changing the texture of the fruit. Pectic substances, hemicellulose, and cellulose undergo depolymerization in ripening fruits, thereby contributing significantly to tissue softening (Proctor and Peng, 1989). As apples usually soften while ripening, the activity of some enzymes, such as pectinesterase and $\beta$-galactosidase, increases

Received for publication 12 July 1990. Accepted for publication 9 Oct. 1991. This work was financially supported by the Comisión Interministerial de Ciencia y Tecnologia (CICYT, ALI89-0101$\mathrm{C} 02$ ). The cost of publishing this paper was defrayed in part by the payment of page charges. Under postal regulations, this paper therefore must be hereby marked advertisement solely to indicate this fact. throughout the process, as does the content in the polyuronide soluble fraction as a result of the cleavage of some interpolymer bonds (Bartley, 1974).

The changes in the various pectic fractions, i.e., water-soluble (WSP), chelatorsoluble (CSP), and hydrochloric acid-soluble (HASP) pectin, throughout fruit ripening is of interest because the softening of apples is related to the contents of these fractions. They would be especially important if a decrease in the insoluble pectin content (HASP fraction) increased the risk of fruit deterioration as it accumulates and, thus, may favor the penetration of pathogens into the fruit. Similarly, the juice yield of the fruit is determined by its degree of ripeness, and the expressible juice yield is reportedly related to the cleavage of interpolymer bonds, the hydroscopic swelling of the wall, and the softening of the apple cell walls (Knee, 1973).

Soluble pectin plays an active role in the clarification of apple juice, upon which it acts as a protective colloid usually bound to proteins to form electronegative particles (Yamasaki et al., 1964). Its occurence increases the viscosity of the medium, which in turn decreases the sedimentation rate of the particles forming clots during clarification.

The aim of this work was to monitor pectic fractions (WSP, CSP, and HASP) 


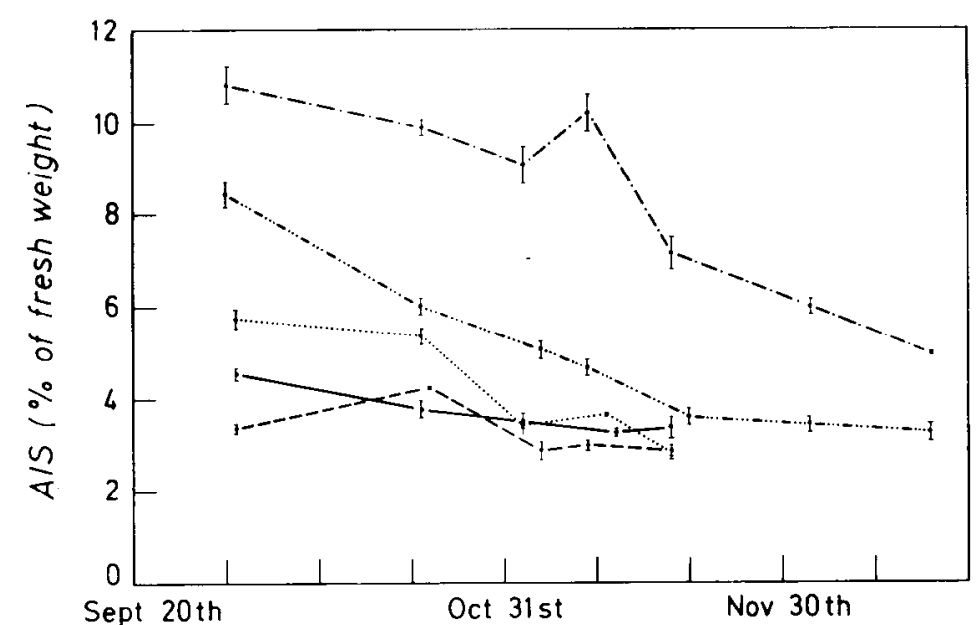

Fig. 1. Variation of the alcohol-insoluble solid (AIS) fraction during ripening of apples 'Picona Rayada' (-), 'Duron Arroes' (-•-), 'Raxao' (- ), 'Collaos' $(-\ldots-)$, and 'Meana'

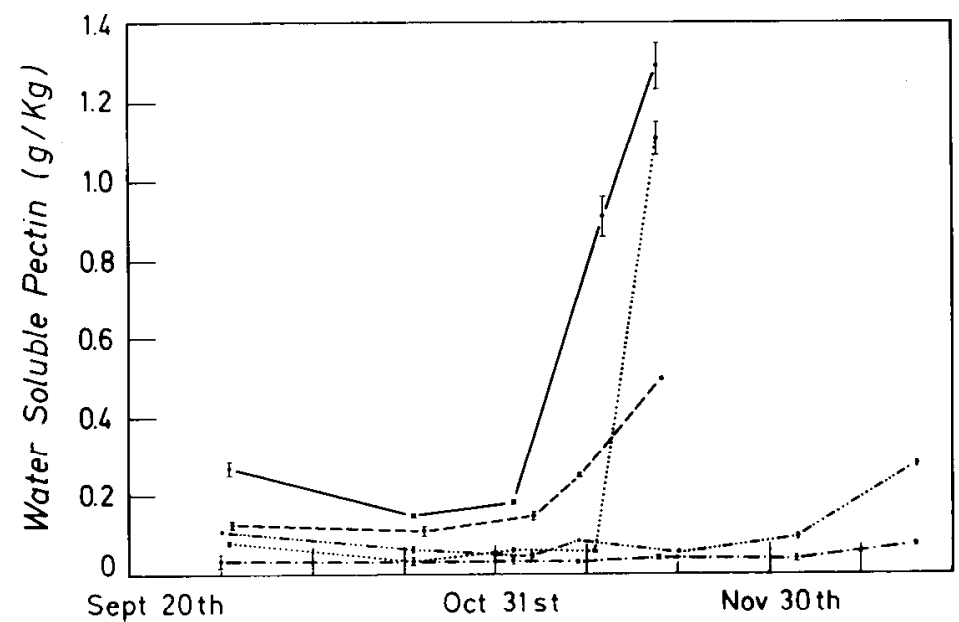

Fig. 2. Changes in the WSP fraction during ripening of apples 'Picona Rayada' (-), 'Duron Arroes' $(-\bullet)$, 'Raxao' $(--)$, 'Collaos' $(-\ldots-)$, and 'Meana' (.....).

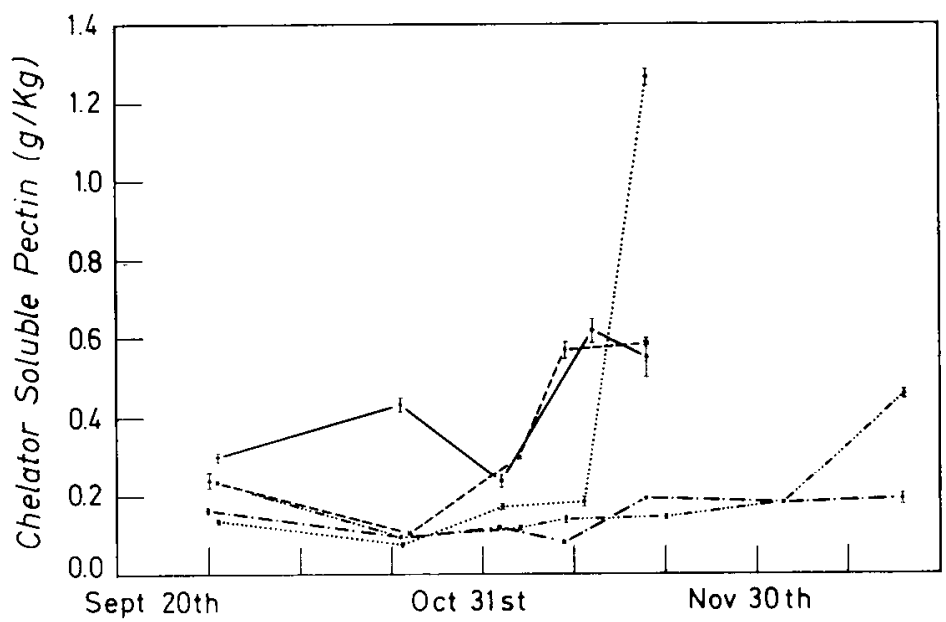

Fig. 3. Changes in the CSP fraction during ripening of apples 'Picona Rayada' (-), 'Duron Arroes' $(-\bullet)$, 'Raxao' $(--)$, 'Collaos' $(-\ldots-)$, and 'Meana' $(. . .$.$) .$

throughout the ripening of five Asturian apple cultivars commonly used in making cider.

Fruit sampling. Specimens of five apple cultivars commonly grown at the Centro de Experimentación Agraria of Villaviciosa,
Asturias, Spain ['Picona Rayada' (bittersweet), 'Raxao' (sharp), 'Meana' (bitttersharp), 'Duron Arroes' (sweet), and 'Collaos' (mild sharp)] were sampled throughout the fruit ripening period on the tree between Sept. and Dec. 1987. The collected specimens were immediately processed for subsequent analyses.

Alcohol-insoluble solids. The alcohol-insoluble solids (AIS) fraction was processed by a method developed at the Station de Recherches Cidricoles et de Biotechnologie Végétale (INRA), Rennes, France. Between 100 and $200 \mathrm{~g}$ of apple was blended with boiling ethanol in a 40:60 (w/w) ratio. The mixture then was filtered through a porous glassy membrane (G-3) and washed with two 1 -liter portions each of $60 \%(\mathrm{v} / \mathrm{v})$ ethanol at the boiling point and at room temperature. The filtrate from the latter washing was subjected to the Molish test to check for the absence of soluble sugars in the filtration cake. The residue was allowed to dry overnight at $40 \mathrm{C}$; once dry, its weight was used to evaluate the AIS content of the sample.

Pectic fractions. The extraction of pectin fractions was carried out by a method developed at INRA.

Between 0.6 and $1.0 \mathrm{~g}$ of pulverized AIS was sequentially extracted as follows:

1) Water-soluble: The WSP fraction was obtained from three aqueous extractions (240 $\mathrm{ml}$ each). Extraction was at $25 \mathrm{C}$ with a shaking of 30,30 , and 15 rein, respectively. The extracts were made up to 1 liter with distilled water and stored for subsequent analysis.

2) Chelator-soluble: The CSP fraction was also extracted three times at $25 \mathrm{C}$ by using $120 \mathrm{ml}$ of $0.75 \%$ ammonium oxalate each time and shaking for 30,15 , and 15 rein, respectively. The extracts were made up to $500 \mathrm{ml}$ with distilled water before being stored.

3) Hydrochloric acid-soluble: The HASP fraction was extracted with three 240-ml portions of $0.05 \mathrm{M} \mathrm{HC} 1$ by shaking for 45 min at $85 \mathrm{C}$ each time. The extracts were made up to 1 liter with distilled water.

The fractioned pectin was measured as total galacturonic acid according to the methods of Kitner and Van Buren (1982) and Thibault (1979) by incubation with sulfuric acid and subsequent color development with alkaline m-hydroxydiphenyl. The process was monitored spectrophotometrically at $520 \mathrm{~nm}$ on a Perkin Elmer Landa 5 instrument (Norwalk, Corm.).

The quantity of AIS decreased throughout ripening in all five apple cultivars studied (Fig. 1). The variations in content were quite small in the final stage of ripening, which is consistent with the stabilization of fruit size during that period and lessens the effect of dilution. The WSP and CSP fractions increased in the final stage of ripening (Figs. 2 and 3). The increase in WSP was particularly marked in 'Meana' and 'Picona Rayada', while the increase in the CSP fraction was substantial in 'Meana'. This different pattern appears to be the result of the enzymatic activity in the final stage of apple ripening that causes the solubilization of structural carbohydrates in the cell wall (Knee, 1973; Proctor and Peng, 1989).

The HASP fraction accounts for by far the greatest part of extracted pectin (Fig. 4). This fraction increases up to the final stage of fruit ripening and then starts to decrease as the 


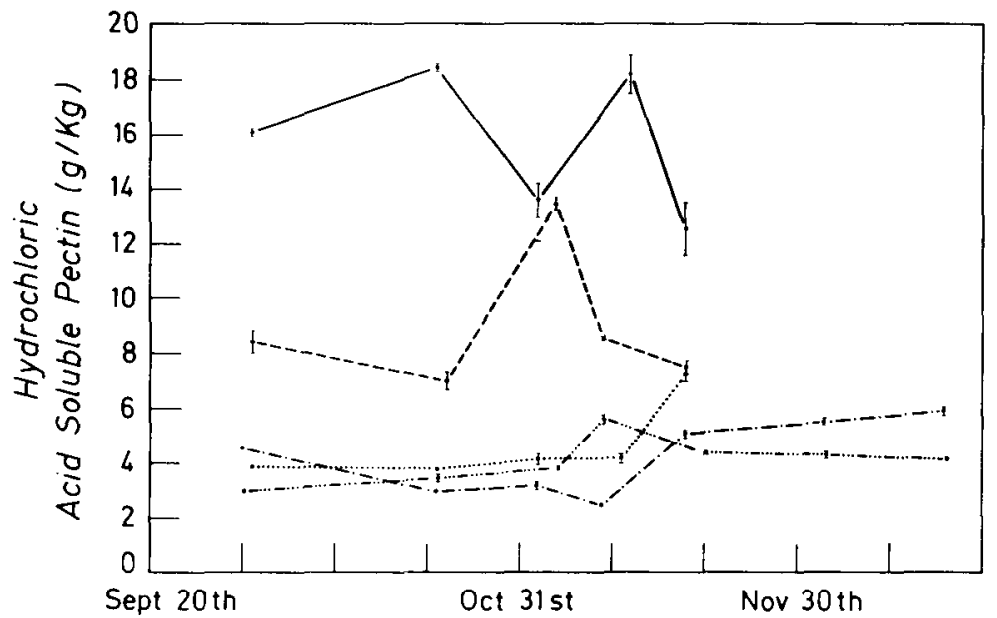

Fig. 4. Changes in the HASP fraction during ripening of apples 'Picona Rayada' (-), 'Duron Arroes' $(-\cdot-)$, 'Raxao' $(--)$, 'Collaos' $(-\ldots-)$, and 'Meana' $(\ldots \ldots)$. .

WSP and CSP fractions begin to increase. Thus, a close relationship between WSP, CSP, and HASP fractions is suggested. Also, the decrease in the HASP fraction in the final stage of ripening-particularly in 'Picona Rayada' and 'Raxao'-is larger than the sum of the increases in the WSP and CSP fractions, which prompts the depolymerization of pectic polysaccharides in the cell wall.

The optimal dates for fruit processing of the five cultivars ('Collaos', 5-10 Dec.; 'Meana', 10-20 Nov.; 'Raxao', 1-10 Nov.;
'Picona Rayada', 5-15 Nov.; 'Duron Arroes', 25 Dec.- 5 Jan.) in the 1987-88 vintage were determined by the fructose : malic acid ratio and the starch content (Lugol index). An increase in the WSP fraction and a decrease in the HASP content was detected in these optimal periods.

Our findings suggest that the WSP and HASP contents could be used to determine the optimal date for cider apple processing, because the WSP fraction is readily extracted in fruit processing and thereby influences technological aspects of clarification and the sensory properties of the cider. Also, the decrease in the HASP fraction of insoluble pectins will affect the quality of the raw material and the amount of expressible juice obtained in fruit milling and pressing.

\section{Literature Cited}

Bartley, I.M. 1974. Beta-galactosidase activity in ripening apples. Phytochemistry 13:2107-2111.

De Vries, J. A., F.M. Rombouts, G.J. Voragen, and W. Pilnik. 1982. Enzymic degradation of apple pectins. Carbohydrate Polymers 2:25-33.

Kintner, P.K. and J.P. Van Buren. 1982. Carbohydrate interference and its correction in pectin analysis using the m-hydroxydiphenyl method. J. Food Sci. 47:756-759.

Knee, M. 1973. Polysaccharide changes in cell walls of ripening apples. Photochemistry 12:1543-1549.

Meurens, M. 1977. Les substances pectiques clans la technologies des jus de pommes. PhD Diss., Catholic Univ. of Louvain, France.

Proctor, A. and L.C. Peng. 1989. Pectin transitions during blueberry fruit development and ripening. J. Food Sci. 54:385-387.

Saulnier, L. and J.M. Brillouet. 1988. Structural studies of pectic substances from the pulp of grape berries. Carbohydrate Res. 182:63-78.

Thibault, J.F. 1979. Automatisation du dosage des substances pectiques par la méthode aux m-hydroxydiphenyl. Lebensm. wis. u. Technol. 12:247-251.

Yamasaki, M., T. Yasui, and K. Arima. 1964 Pectic enzymes in the clarification of apple juice. Part I. Study on the clarification in a simplified model. Agr. Biol Chem. 28:779-787. 